\title{
COMPETITIVIDADE DOS SECTORES MANUFACTUREIROS DE ALEMAÑA E ESPAÑA, 1995-2015: ANÁLISE DA VANTAXE ABSOLUTA DE CUSTO CON DATOS DE PANEL DINÁMICO
}

Fahd BOUNDI-CHRAKI

fboundi@ucm.es,

Universidade Complutense de Madrid

Resumo: A presente investigación ten como obxectivo identificar os factores que explican a mellor posición competitiva dos sectores manufactureiros alemáns en relación cos españois durante o período 1995-2015. Con base na teoría da vantaxe absoluta de custo de Shaikh, contrástase a hipótese de que, para o devandito período, os termos reais de intercambio entre os sectores manufactureiros de España e de Alemaña atópanse regulados polos niveis relativos dos seus custos laborais unitarios reais. A este fin, constrúese un modelo dinámico de datos de panel conformado polos once sectores manufactureiros da base EU KLEMS 2017, o cal revela que entre as tres variables existe unha relación estable a longo prazo.

Palabras chave: relacións reaies de intercambio, vantaxe absoluta de custo, competencia, custos laborais unitarios, cointegración.

Código JEL: B51, C01, F10, F20.

\section{Competitiveness of the German and Spanish manufacturing sectors, 1995-2015: an analysis of absolute cost advantage using dynamic panel data}

\section{Abstract}

The main goal of this paper is to identify the explanatory factors on the competitive position of manufacturing sectors from Germany and Spain during 1995-2015. Based on Shaikh's theory of absolute cost advantage, we try to test the hypothesis that the real terms of exchange are regulated by real unit labor costs. In order to do so, we elaborate a dynamic data model through the EU KLEMS 2017 database, which reveals that there is a stable long-term relationship between the three variables.

Key word: Real terms of trade, absolute cost advantage, unit labour cost, cointegration. JEL code : B51, C01, F10, F20.

\section{Introdución}

A libre circulación de mercadorías, de capitais e de traballo dende 1993 e o nacemento en 2002 da zona euro, tivo a ben agudizar os desequilibrios da Unión Europea (en adiante, UE). Baste sinalar aquí que, conforme aos datos de Eurostat, en 2015 Alemaña gozaba dun superávit na balanza comercial intraUE de bens manufactureiros de 71.186,6 millóns de euros correntes ${ }^{1}$, namentres que España ten para ese mesmo ano un déficit intraUE de 5.193 millóns de euros correntes ${ }^{2}$.

O saldo comercial de bens manufacturados entre España e Alemaña é aínda máis revelador, se encaixa, dado que o déficit comercial rexistra -10.052 millóns de euros

\footnotetext{
1 Os datos de Eurostat indican que en 2015 o valor monetario das exportacións e as importacións de bens manufactureiros de Alemaña coa UE foi de 692.808,216 millóns de euros correntes e 621.621,654 millóns de euros correntes, respectivamente.

2 Conforme a Eurostat, en 2015 as exportacións de bens manufactureiros de España cara a UE chegaron a 165.643,708 millóns de euros correntes, namentres que as importacións foron de 170.836,815 millóns de euros correntes.
} 
correntes en 201533. Perante estes datos, o obxectivo da presente investigación é identificar os factores que explican a mellor posición da industria manufactureira alemá con respecto á española durante o período 1995-20154.

Para este propósito, pártese da teoría da vantaxe absoluta de custo desenvolvida por Shaikh (2016), conforme á cal dinámica fundamental dos tipos de cambio reais efectivos se atopa regulada a longo prazo polos niveis relativos dos custos unitarios de produción. Hai que sinalar que o enfoque teórico de Shaikh foi amplamente contrastado empiricamente para varios países (Guerrero, 1995; Martínez-Hernández, 2010, 2017; Góchez \& Tablas, 2013; Shaikh, 2016; Boundi Chraki, 2017), se ben hai que engadir que a principal novidade deste traballo é que se trata da primeira análise a nivel intrasectorial a través da metodoloxía dos datos de panel dinámicos no contexto da eurozona.

A investigación estrutúrase en tres apartados. No primeiro, faise unha breve definición dos elementos centrais da teoría da vantaxe absoluta de custo, especifícase a hipótese da investigación, preséntanse as bases de datos utilizadas e, finalmente, detállase o modelo econométrico. A segunda epígrafe adícase a analizar os resultados econométricos. Por último, resúmense as principais conclusións.

\section{Vantaxe absoluta de custo, hipótese, base de datos e modelo econométrico}

Tal e como argumenta Shaikh (2016), a competencia intra e intersectorial 5 implica que os termos reais de intercambio entre as nacións deben estar supeditados á vantaxe absoluta de custo. Id est, os tipos de cambio reais atópanse regulados a longo prazo polos custos laborais unitarios reais (en adiante, CLUR) daquelas empresas que posúen as mellores condicións técnicas de produción reproducibles de cada país.

Despréndese, pois, que a vantaxe absoluta de custo intrasectorial está dada conxuntamente polos salarios reais e a produtividade real das devanditas empresas reguladoras (Guerrero, 1995; Shaikh, 2016; Góchez \& Tablas, 2013; Boundi Chraki, 2017). Isto quere dicir que o país máis produtivo será máis competitivo có país con salarios máis baixos, como e canto a diferenza en produtividade sexa máis alta cá diferenza en salarios, e viceversa (Guerrero, 1995).

Así, con base nos elementos que articulan a teoría da vantaxe absoluta de custo de Shaikh, a hipótese xeral da investigación aplícase do seguinte modo: os termos reais de intercambio entre os sectores manufactureiros de España e de Alemaña ao longo do período 1995-2015, atópanse regulados polos niveis relativos dos seus CLUR.

\footnotetext{
${ }^{3}$ Conforme aos datos de Eurostat, o valor monetario dos fluxos de exportacións e importacións de bens manufactureiros de España con Alemaña en 2015 foi, respectivamente, de 25.993,68 millóns de euros correntes e 36.045,77 millóns de euros correntes.

4 A análise de estudo acóutase a 1995-2015, como e canto a base EU KLEMS 2017 soamente ofrece series de emprego, valor engadido bruto, prezos sectoriais e horas traballadas para o devandito espazo de tempo.

5 Shaikh subliña que a competencia intrasectorial revela unha tendencia cara á igualación dos prezos de mercado, na medida en que as empresas peor dotadas tecnicamente se atopan na obriga de abatir os seus prezos ata o nivel que someten as empresas con técnicas de produción superiores. Estas últimas, vale dicir, gozan de taxas de beneficio máis elevadas cás dos seus competidores, regulando deste xeito o movemento do capital que tende a nivelar as rendibilidades entre os sectores [competencia intersectorial].
} 
Polo anterior, infírese que o tipo de cambio real efectivo do i-enésimo sector manufactureiro de España con respecto ao i-enésimo sector manufactureiro de Alemaña debe estar estreitamente relacionado cos CLUR 6 relativos (en adiante, CLURR):

$$
T C R_{i t} \equiv e_{t} * \frac{P_{i t}^{*}}{P_{t t}} \cong C L U R R_{i t}=\frac{C L U R_{i t}^{*}}{C L U R_{i t}}=\frac{\left(\frac{W R_{i t}^{*}}{Y L R_{i t}^{*}}\right)}{\left(\frac{W R_{i t}}{Y L R_{i t}}\right)}=\frac{\left(\begin{array}{c}
W N_{i t}^{*} \\
\frac{I P C A_{i}^{*}}{Y L N_{i t}^{*}} \\
I P V_{i t}^{*}
\end{array}\right)}{\left(\frac{W N_{i t}}{I P C A_{t}}\right.}
$$

Onde:

$T C R_{i t}$ = tipo de cambio real efectivo do i-enésimo sector manufactureiro de España con respecto ao i-enésimo sector manufactureiro de Alemaña no momento t.

$e_{t}=$ tipo de cambio nominal efectivo de España con respecto a Alemaña no momento $t$ (ata 2002 representa a relación peseta/ marco alemán).

$P_{i t}^{* \prime}=$ prezos do i-enésimo sector manufactureiro de Alemaña.

$P_{i t}=$ prezos do i-enésimo sector manufactureiro de España.

$C L U R R_{i t}=$ custo laboral unitario real relativo no momento $t$.

$C L U R_{i t}^{*}=$ custo laboral unitario real do i-enésimo sector manufactureiro de Alemaña.

$C L U R_{i t}=$ custo laboral unitario real do i-enésimo sector manufactureiro de España.

$W R_{i t}^{*}=$ salario por hora en euros constantes de 1999 do i-enésimo sector manufactureiro de Alemaña.

$Y L R_{i t}^{*}=$ produtividade aparente do traballo por hora en euros constantes de 1999 do ienésimo sector manufactureiro de Alemaña.

$W R_{i t}=$ salario por hora en euros constantes de 1999 do i-enésimo sector manufactureiro de España.

$Y L R_{i t}=$ produtividade aparente do traballo por hora en euros constantes de 1999 do ienésimo sector manufactureiro de España.

$W N_{i t}^{*}=$ salario por hora en euros correntes do i-enésimo sector manufactureiro de Alemaña.

${ }^{6}$ É importante subliñar que os índices dos prezos dos salarios, os valores engadidos brutos e a formación bruta de capital fixo ten como ano base 1999. Elíxese ese ano xa que o 1 de xaneiro de 1999 se estableceu o tipo de cambio nominal fixo entre as divisas dos once Estados fundadores e 0 euro. 
$I P C A_{t}^{*}=$ índice de prezos ao consumo harmonizado de Alemaña con base en 1999.

$Y L N_{i t}^{*}$ = produtividade aparente do traballo por hora en euros correntes do i-enésimo sector manufactureiro de Alemaña.

$I P V_{i t}^{*}=$ índice do valor engadido bruto do i-enésimo sector manufactureiro de Alemaña con base en 1999.

$W N_{i t}=$ salario por hora en euros correntes do i-enésimo sector manufactureiro de España.

$I P C A_{t}=$ índice de prezos ao consumo harmonizado de España con base en 1999.

$Y L N_{i t}=$ produtividade aparente do traballo por hora en euros correntes do i-enésimo sector manufactureiro de España.

$I P V_{i t}=$ índice do valor engadido bruto do i-enésimo sector manufactureiro de España con base en 1999.

$\mathrm{t}=(1995 \ldots 2015)$.

Adicionalmente, queremos considerar un segundo factor que coadxuva a dilucidar o movemento a longo prazo do $\mathrm{TCR}_{\mathrm{it}}$ : a formación bruta de capital fijo a prezos constantes de 1999 do i-enésimo sector manufactureiro español (en adiante, $\mathrm{INV}_{\mathrm{it}}$ ). A escolla desta variable de ningún xeito é fortuíta, na medida en que permite captar o efecto do ciclo económico industrial, o cambio técnico e a elasticidade prezo-cantidade das importacións dos bens de capital sobre a competitividade do i-enésimo sector manufactureiro español con respecto ao do seu equivalente alemán (Boundi Chraki, 2017).

De igual maneira, hai que sinalar que a fin de medir a influencia da entrada en circulación do euro en 2002 sobre TCR it $_{\text {t }}$ crase unha variable ficticia (dummy) que toma como valor 0 dende 1995 ata 2001 ( $\delta 1995-2001=0)$, e valor 1 dende 2002 ata $2015(\delta 2002-2015=1)$. A devandita variable ficticia denomínase, en adiante, $\delta_{1}$ EUR.

Por outra banda, a base de datos dende a cal recolleuse a información necesaria para construír o modelo econométrico é a EU KLEMS 2017. Tal e como indican O'Mahony e Timmer (2009), e Ark e Jäger (2017), a EU KLEMS 2017 está totalmente harmonizada co novo Sistema Europeo de Contabilidade Nacional (en adiante, ESA 2010 polas súas siglas en inglés). Ademais, segue a clasificación industrial da Nomenclatura Estatística de Actividades económicas da Comunidade Europea revisión 2 (en adiante, NACE 2) compatible coa International Standard Industrial Classification of All Economic Activities revisión 4 (en adiante, ISIC Rev. 4).

Os datos sobre produción, valor engadido bruto, prezos e formación bruta de capital fixo son concordantes coas estatísticas oficiais de Eurostat, namentres que as series de emprego da EU KLEMS 2017 se axeitan á metodoloxía de European Labour Force Survey (en adiante, LFS) e da Structure of Earning Survey (en adiante, SES). En resumo, a EU KLEMS 2017 eríxese como a base axeitada para acadar o obxectivo da investigación, aínda máis cando agrupa en once os sectores manufactureiros de España e de Alemaña permitindo así a súa análise comparada (véxase a táboa 1). 
Táboa 1. Clasificación dos sectores manufactureiros de España e Alemaña conforme á EU KLEMS 2017

\begin{tabular}{|l|c|}
\hline Sector & $\begin{array}{c}\text { Código } \\
\text { NACE 2 }\end{array}$ \\
\hline Produtos alimenticios, bebidas e tabaco & $10-12$ \\
\hline Téxtil, prendas, coiro e calzado & $13-15$ \\
\hline Madeira, papelaría e actividades de edición & $16-18$ \\
\hline Coque e refinamento de petróleo & 19 \\
\hline Industria química & $20-21$ \\
\hline $\begin{array}{l}\text { Caucho, produtos de plástico e outros produtos } \\
\text { minerais non metálicos }\end{array}$ & $22-23$ \\
\hline $\begin{array}{l}\text { Metais comúns e produtos metálicos, agás } \\
\text { maquinaria e equipo }\end{array}$ & $24-25$ \\
\hline Equipo óptico e eléctrico & $26-27$ \\
\hline Maquinaria e equipo n.c.p & 28 \\
\hline Equipo de transporte & $29-30$ \\
\hline $\begin{array}{l}\text { Outras manufacturas; reparación e instalación } \\
\text { de maquinaria e equipo }\end{array}$ & $31-33$ \\
\hline
\end{tabular}

Fonte: elaboración do autor conforme á EU KLEMS 2017

Pola súa banda, os IPCA de España e de Alemaña obtéronse de Eurostat, sendo este un indicador común da inflación para os países da UE. A súa importancia radica en que o IPCA toma en consideración o gasto do consumo das familias en toda a UE, id est: o realizado polos residentes e os non residentes. Así, a ecuación do $\mathrm{TCR}_{\mathrm{it}}$ pódese escribir da seguinte forma:

$$
T C R_{i t}=f\left(C L U R R_{i t}, I N V_{i t}, \delta_{1} E U R\right)
$$

Dado que a análise dos termos reais de intercambio se realiza a nivel intrasectorial, procedeuse a construír un modelo de datos de panel que aglutina cada i-enésimo sector manufactureiro durante o período 1995-2015. Así mesmo, decidiuse transformar as variables $\mathrm{TCR}_{\mathrm{it}}$, CLURR $\mathrm{it}$ e $\mathrm{INV}_{\text {it }}$ en logaritmos neperianos co obxecto de atopar as variacións anuais e as elasticidades entre elas. A especificación do modelo de regresión múltiple estimado por mínimos cadrados ordinarios (en adiante, $\mathrm{MCO}$ ) escríbese así:

$$
L O G\left(T C R_{i t}\right)=\beta_{0}+\beta_{1} L O G\left(C L U R R_{i t}\right)+\beta_{2} L O G\left(I N V_{i t}\right)+\delta_{1} E U R+\varepsilon_{i t}
$$

Onde: $L O G=$ logaritmo neperiano. $\beta_{0}=$ constante. $\beta_{i}=$ coeficientes múltiples de determinación. ${ }^{\varepsilon_{i t}}=$ termo erro.

Os outros termos foron definidos previamente. Chegados a este punto, hai que sinalar que na análise de cointegración é conditio sine qua non que as variables en nivel conteñan raíz unitaria de grao I (1). Polo anterior, óptase polas probas de raíces unitarias de Breitung (2000), de Maddala e Wu (1999) (en adiante, MW) e de Hadri (2000). As hipóteses nulas dos devanditos contrastes recóllense na táboa 2 .

Táboa 2. Hipóteses nulas das probas de raíces unitarias

\begin{tabular}{|c|c|}
\hline Proba & Hipótese nula \\
\hline Breitung $(2000)$ & Proceso común de raíz unitaria \\
\hline Maddala e Wu (1999) & Proceso individual de raíz unitaria \\
\hline Hadri $(2000)$ & Estacionariedade \\
\hline
\end{tabular}

Fonte: elaboración do autor 
Na medida en que as variables sexan non estacionarias en nivel e integradas da misma orde, poderase verificar estatisticamente que elas se atopan cointegradas a través das probas de Pedroni (1999) e de Kao (1999) con base en Engle e Granger (1987). Así mesmo, o vector de cointegración estímase mediante o MCO dinámico (en adiante, DOLS polas súas siglas en inglés) e o modelo de MCO totalmente modificado (en adiante, FMOLS polas súas siglas en inglés) (Stock \& Watson, 1993; Pedroni, 1999, 2001). Realizadas as correspondentes aclaracións teóricas e metodolóxicas, despois procédese á análise dos resultados e á comprobación da hipótese de investigación.

\section{Evolución da produtividade, o salario e a relación de custos unitarios en España e Alemaña, 1995-2015}

Na táboa 3, obsérvase que para o conxunto da industria manufactureira alemá a produtividade real pasou de 40,58 euros7/ hora en 2000 a 52,40 euros/hora en 2007, namentres que o total das manufactureiras españolas incrementaron a súa produtividade real dende 21,30 euros/ hora en 2000 ata 24,87 euros/ hora en 2007.

Traducido en taxas medias acumulativas, a produtividade real en Alemaña creceu o 3,72\% anual, namentres que en España un 2,24\% anual. É dicir, a diferenza en produtividade aumentou de 1,9 ata 2,11 durante o lapso 2000-2007.

Os cinco sectores alemáns que incrementan máis a súa distancia con respecto aos equivalantes españois durante o devandito período son, en orde de magnitude: i) caucho, produtos de plástico e outros produtos minerais non metálicos; ii) metais comúns e produtos metálicos, agás maquinaria e equipo; iii) equipo óptico e eléctrico; iv) industria química; e v) madeira, papelaría e actividades de edición (véxase a táboa 3) Porén, tres sectores alemáns viron reducida a súa diferenza en produtividade, a saber: i) produtos alimenticios, bebidas e tabaco; ii) coque e refinamento de petróleo; e iii) equipo de transporte (véxase a táboa 3).

Táboa 3. Produtividade por hora traballada medida en euros constantes de 1999 para cada sector manufactureiro de España e de Alemaña

\begin{tabular}{|l|c|c|c|c|c|c|c|c|}
\hline Variable & \multicolumn{4}{|c|}{ España } & \multicolumn{5}{|c|}{ Alemaña } \\
\hline Sector/ período & $\mathbf{1 9 9 5}$ & $\mathbf{2 0 0 0}$ & $\mathbf{2 0 0 7}$ & $\mathbf{2 0 1 5}$ & $\mathbf{1 9 9 5}$ & $\mathbf{2 0 0 0}$ & $\mathbf{2 0 0 7}$ & $\mathbf{2 0 1 5}$ \\
\hline $\begin{array}{l}\text { Produtos alimenticios, bebidas e } \\
\text { tabaco }\end{array}$ & 22,95 & 21,78 & 26,25 & 24,54 & 29,45 & 30,37 & 29,53 & 27,90 \\
\hline Téxtil, prendas, coiro e calzado & 13,02 & 13,58 & 17,24 & 20,94 & 22,56 & 26,63 & 35,07 & 36,61 \\
\hline $\begin{array}{l}\text { Madeira, papelaría e actividades de } \\
\text { edición }\end{array}$ & 22,25 & 22,18 & 23,77 & 28,50 & 29,92 & 36,12 & 42,56 & 47,02 \\
\hline Coque e refinamento de petróleo & 235,8 & 217,4 & 184,0 & 108,5 & 137,2 & 187,9 & 139,7 & 92,77 \\
& 1 & 7 & 9 & 0 & 7 & 1 & 5 \\
\hline Industria química & 38,87 & 40,42 & 48,29 & 55,43 & 50,34 & 63,44 & 87,42 & 87,28 \\
\hline $\begin{array}{l}\text { Caucho, produtos de plástico e } \\
\text { outros } \\
\text { producos minerais non metálicos }\end{array}$ & 23,42 & 25,30 & 24,86 & 31,46 & 32,55 & 35,78 & 46,21 & 47,58 \\
\hline $\begin{array}{l}\text { Metais comúns e produtos metálicos, } \\
\text { agás maquinaria e equipo }\end{array}$ & 21,41 & 24,34 & 22,61 & 34,93 & 29,16 & 34,58 & 38,79 & 39,95 \\
\hline Equipo óptico e eléctrico & 24,96 & 22,70 & 30,84 & 39,27 & 39,31 & 54,89 & 83,45 & 97,49 \\
\hline Maquinaria e equipo n.c.p & 21,70 & 23,38 & 26,63 & 32,29 & 36,47 & 39,93 & 47,31 & 40,78 \\
\hline Equipo de transporte & 25,52 & 24,02 & 38,17 & 50,41 & 48,03 & 46,04 & 68,86 & 85,38 \\
\hline $\begin{array}{l}\text { Outras manufacturas; reparación e } \\
\text { instalación de maquinaria e equipo }\end{array}$ & 14,45 & 16,70 & 20,11 & 26,39 & 26,06 & 31,66 & 42,01 & 37,14 \\
\hline Total de manufacturas & 20,92 & 21,30 & 24,87 & 30,42 & 34,66 & 40,58 & 52,40 & 54,59 \\
\hline
\end{tabular}

Fonte: elaboración do autor en base á EU KLEMS 2017

${ }^{7}$ A unidade de medida da produtividade real está expresada en euros constantes de 1999. Cabe recordar que no apartado metodolóxico especificouse que todas as variables se atopan deflactadas polos seus correspondentes índices de prezos con ano base 1999. 
Hai que dicir que este vigoroso aumento da produtividade real de Alemaña está asociado con factores técnico-produtivos e institucionais. En primeiro lugar, Muñoz de Bustillo e Fernández Macías (2007) recalcan que en Alemaña se deseñaron métodos para a organización do traballo que consistiron facer un uso máis eficiente do capital instalado, o cal coadxuvou a elevar a produtividade real por enriba da media da UE.

Así mesmo, Luque e Palazuelos (2015) apuntan que nos sectores manufactureiros alemáns houbo un importante proceso de capitalización do traballo [maior relación capital/ traballo] e unha substancial mellora da eficiencia produtiva mediante o cambio técnico [relación produto/capital máis elevada] durante a fase de expansión do ciclo económico (1995-2007). Consecuentemente, as empresas alemás acadaron aumentos da produtividade real superiores á dos seus competidores españois, grazas á adopción de técnicas de produción máis eficientes e intensivas en capital fixo (Boundi Chraki, 2017).

En segundo termo, a nivel institucional Becker e Dietz (2004) destacan que a cooperación en investimento e desenvolvemento (en adiante, I\&D) permitiu ás empresas manufactureiras alemás obter os recursos internos para completar os procesos de innovación, inducindo deste xeito efectos positivos sobre a produtividade a través dos spillovers tecnolóxicos e os encadeamentos produtivos. Máis aínda, as políticas rexionais alemás favoreceron as condicións para a formación de clústeres industriais para aproveitar as vantaxes derivadas das economías de aglomeración (Götz \& Jankowska, 2017).

Seifert e Massa-Wirth (2005) aducen que os pactos para o emprego e a competitividade (en adiante, PEC) contribuíron significativamente nas ganancias de competitividade, na medida en que as empresas alemás se dotaron dunha maior flexibilidade interna para arrostrar os diferentes escenarios económicos. É dicir, as empresas alemás atopábanse capacitadas para determinar o tempo da xornada laboral ou o salario en función do contexto macroeconómico e as rendibilidades obtidas.

Táboa 4. Salario por hora traballada medido en euros constantes de 1999 para cada sector manufactureiro de España e de Alemaña

\begin{tabular}{|l|c|c|c|c|c|c|c|c|}
\hline Variable & \multicolumn{2}{|c|}{ WR España } & \multicolumn{2}{|c|}{ WR Alemaña } \\
\hline \multicolumn{1}{|c|}{ Sector/ período } & $\mathbf{1 9 9 5}$ & $\mathbf{2 0 0 0}$ & $\mathbf{2 0 0 7}$ & $\mathbf{2 0 1 5}$ & $\mathbf{1 9 9 5}$ & $\mathbf{2 0 0 0}$ & $\mathbf{2 0 0 7}$ & $\mathbf{2 0 1 5}$ \\
\hline $\begin{array}{l}\text { Produtos alimenticios, } \\
\text { bebidas e tabaco }\end{array}$ & 12,00 & 11,37 & 12,05 & 11,33 & 19,09 & 20,34 & 19,13 & 20,64 \\
\hline $\begin{array}{l}\text { Téxtil, prendas, } \\
\text { coiro e calzado }\end{array}$ & 9,31 & 8,24 & 9,95 & 9,24 & 17,56 & 19,65 & 19,72 & 21,49 \\
\hline $\begin{array}{l}\text { Madeira, papelaría e } \\
\text { actividades de edición }\end{array}$ & 12,39 & 11,68 & 13,12 & 12,68 & 22,60 & 23,93 & 22,08 & 21,87 \\
\hline $\begin{array}{l}\text { Coque e refinamiento } \\
\text { de petróleo }\end{array}$ & 31,07 & 31,78 & 29,68 & 34,47 & 28,73 & 42,18 & 43,92 & 40,98 \\
\hline Industria química & 21,46 & 19,23 & 20,71 & 19,02 & 29,18 & 33,01 & 32,50 & 36,22 \\
\hline $\begin{array}{l}\text { Caucho, produtos de } \\
\text { plásticoe outros produtos } \\
\text { minerais non metálicos }\end{array}$ & 13,79 & 13,78 & 14,78 & 14,96 & 21,78 & 23,09 & 21,82 & 22,99 \\
\hline $\begin{array}{l}\text { Metais comúns e produtos } \\
\text { metálicos , agás } \\
\text { maquinaria e equipo }\end{array}$ & 13,58 & 13,18 & 14,85 & 14,98 & 24,31 & 25,73 & 25,23 & 26,14 \\
\hline Equipo óptico e eléctrico & 17,12 & 14,39 & 15,48 & 15,43 & 25,41 & 28,68 & 30,49 & 32,31 \\
\hline Maquinaria e equipo n.c.p & 15,33 & 14,01 & 15,85 & 15,26 & 26,57 & 28,79 & 29,47 & 31,12 \\
\hline Equipo de transporte & 15,93 & 14,19 & 17,82 & 19,20 & 28,41 & 32,58 & 35,57 & 38,92 \\
\hline $\begin{array}{l}\text { Outras manufacturas; } \\
\text { reparación e instalación de } \\
\text { maquinaria e equipo }\end{array}$ & 12,87 & 11,12 & 11,44 & 11,81 & 23,53 & 26,34 & 26,33 & 26,86 \\
\hline Total de manufacturas & 13,69 & 12,68 & 14,18 & 14,06 & 24,30 & 26,82 & 27,17 & 28,87 \\
\hline
\end{tabular}

Fonte: elaboración do autor en base á EU KLEMS 2017 
Con respecto a isto, hai que sinalar que, conforme á táboa 4, a contención salarial para o total das manufacturas foi maior en Alemaña que en España durante 2000-2007, dado que a taxa media acumulativa anual foi, respectivamente, o $0,18 \%$ (de 26,82 euros/ hora a 27,17 euros/ hora) e o 1,61\% (de 12,68 euros/ hora a 14,18 euros/ hora).

Máis concretamente, a diferenza en salarios reais baixou de 2,11 a 1,91, xa que os sectores que conseguiron reducir en maior medida a fenda salarial foron, en orde de importancia: i) Téxtil, prendas, coiro e calzado; ii) madeira, papelaría e actividades de edición; iii) equipo e transportes; iv) metais comúns e produtos metálicos, agás maquinaria e equipo; v) caucho, produtos de plástico e outros produtos minerais non metálicos (véxase a táboa 7 no anexo).

Como consecuencia necesaria do anterior, os CLUR, medidos como índices con base en 1999, revelan que estes baixaron máis en Alemaña que en España durante 2000-2007 (véxase a táboa 5). Para o total das manufacturas alemás e españolas os CLUR caeron $3,41 \%$ e $-0,62 \%$, respectivamente, en $2000-2017$. Os CLURR, como determinantes das relacións reais de intercambio, indican unha perda acumulada da competitividade de España con respecto a Alemaña en torno ao 18\% para o período 2000-2007, xa que caen de 0,99 en 2000 a 0,81 en 2007 (véxase a táboa 6).

Neste senso, os sectores de Alemaña que obteñen maiores ganancias de competitividade son: i) equipo de transporte; ii) caucho, produtos de plástico e outros produtos minerais non metálicos; iii) metais comúns e produtos metálicos, agás maquinaria e equipo; iv) madeira, papelaría e actividades de edición; v) Téxtil, prendas, coiro e calzado (véxase a táboa 6).

Táboa 5. Índice do custo laboral unitario real $(1999=100)$ para cada sector manufactureiro de España e de Alemaña

\begin{tabular}{|l|c|c|c|c|c|c|c|c|}
\hline Variable & \multicolumn{3}{|c|}{ CLUR España } & \multicolumn{3}{c|}{ CLUR Alemaña } \\
\hline Sector/ período & $\mathbf{1 9 9 5}$ & $\mathbf{2 0 0 0}$ & $\mathbf{2 0 0 7}$ & $\mathbf{2 0 1 5}$ & $\mathbf{1 9 9 5}$ & $\mathbf{2 0 0 0}$ & $\mathbf{2 0 0 7}$ & $\mathbf{2 0 1 5}$ \\
\hline $\begin{array}{l}\text { Produtos alimenticios, } \\
\text { bebidas e tabaco }\end{array}$ & 97,51 & 97,39 & 85,60 & 86,12 & 92,84 & 95,91 & 92,73 & $\begin{array}{c}105,9 \\
2\end{array}$ \\
\hline $\begin{array}{l}\text { Téxtil, prendas, } \\
\text { coiro e calzado }\end{array}$ & 112,68 & 95,72 & 90,95 & 69,51 & 101,82 & 96,51 & 73,55 & 76,77 \\
\hline $\begin{array}{l}\text { Madeira, papelaría e } \\
\text { actividades de edición }\end{array}$ & 102,21 & 96,62 & 101,34 & 81,67 & 114,52 & 100,46 & 78,68 & 70,54 \\
\hline $\begin{array}{l}\text { Coque e refinamento } \\
\text { de petróleo }\end{array}$ & 97,52 & 108,17 & 119,32 & 235,12 & 39,04 & 41,87 & 58,62 & 82,40 \\
\hline Industria química & 112,84 & 97,28 & 87,69 & 70,15 & 114,45 & 102,74 & 73,40 & 81,94 \\
\hline $\begin{array}{l}\text { Caucho, produtos de } \\
\text { plástico e outros produtos } \\
\text { minerais non metálicos }\end{array}$ & 105,90 & 97,99 & 106,94 & 85,49 & 103,02 & 99,38 & 72,68 & 74,39 \\
\hline $\begin{array}{l}\text { Metais comúns y produtos } \\
\text { metálicos , agás } \\
\text { maquinaria e equipo }\end{array}$ & 112,60 & 96,14 & 116,58 & 76,13 & 108,94 & 97,22 & 84,98 & 85,49 \\
\hline Equipo óptico e eléctrico & 106,64 & 98,58 & 78,07 & 61,10 & 101,65 & 82,17 & 57,44 & 52,12 \\
\hline Maquinaria e equipo n.c.p & 111,20 & 94,33 & 93,67 & 74,40 & 97,02 & 96,04 & 82,96 & 101,6 \\
\hline Equipo de transporte & 112,60 & 96,14 & 116,58 & 76,13 & 88,96 & 106,45 & 77,69 & 68,58 \\
\hline $\begin{array}{l}\text { Outras manufacturas; } \\
\text { reparación e instalación de } \\
\text { maquinaria e equipo }\end{array}$ & 125,29 & 93,64 & 80,05 & 62,93 & 107,81 & 99,33 & 74,81 & 86,33 \\
\hline Total de manufacturas & 107,08 & 97,44 & 93,28 & 75,62 & 101,94 & 96,10 & 75,39 & 76,89 \\
\hline
\end{tabular}

Fonte: elaboración do autor en base á EU KLEMS 2017

Como consecuencia, conflúen dous factores que dotan aos sectores manufactureiros alemáns a súa vantaxe absoluta de custo en 2000-2007: i) a súa capacidade para 
incrementar a produtividade real por enriba dos seus competidores españois a través de factores técnico-produtivos e institucionais: e ii) a habilidade das empresas de conter o salario real debido á flexibilidade interna. Porén, tal e como se analiza despois, a partir de 2007 esta situación verase modificada pola crise e a recesión (2008-2015).

A este propósito, a correlación positiva entre LOG(TCR) e LOG(INV) exterioriza que, ceteris paribus, o aumento dun $1 \%$ do investimento en maquinaria, equipos e plantas do ienésimo sector manufactureiro español ten como corolario unha depreciación real de arredor do 0,112\% (DOLS) ou o 0,122\% (FOMLS) (véxase a táboa 9 de anexo). Este resultado, por certo, é coherente co esperado, debido a que a competitividade dos sectores manufactureiros se atopa afectada pola fase do ciclo económico, a adquisición de bens de capital, o cambio tecnolóxico e a extensión da escala de produción que consegue elevar a produtividade laboral (Shaikh, 2016; Boundi Chraki, 2017).

Táboa 6. custos laborais unitarios reais relativos (CLUR Alemaña/ CLUR España)

\begin{tabular}{|c|c|c|c|c|}
\hline Variable & \multicolumn{4}{|c|}{ CLURR (CLUR Ale./ CLUR Esp.) } \\
\hline Sector/ período & $\mathbf{1 9 9 5}$ & $\mathbf{2 0 0 0}$ & $\mathbf{2 0 0 7}$ & $\mathbf{2 0 1 5}$ \\
\hline Produtos alimenticios, bebidas e tabaco & 0,95 & 0,98 & 1,08 & 1,23 \\
\hline Téxtil, prendas, coiro e calzado & 0,90 & 1,01 & 0,81 & 1,10 \\
\hline Madeira, papelaría e actividades de edición & 1,12 & 1,04 & 0,78 & 0,86 \\
\hline Coque e refinamento de petróleo & 0,40 & 0,39 & 0,49 & 0,35 \\
\hline Industria química & 1,01 & 1,06 & 0,84 & 1,17 \\
\hline $\begin{array}{c}\text { Caucho, produtos de plástico e outros produtos } \\
\text { minerais non metálicos }\end{array}$ & 0,97 & 1,01 & 0,68 & 0,87 \\
\hline $\begin{array}{c}\text { Metais comúns e produtos metálicos, agás } \\
\text { maquinaria e equipo }\end{array}$ & 0,97 & 1,01 & 0,73 & 1,12 \\
\hline Equipo óptico e eléctrico & 0,95 & 0,83 & 0,74 & 0,85 \\
\hline Maquinaria e equipo n.c.p & 0,87 & 1,02 & 0,89 & 1,37 \\
\hline Equipo de transporte & 0,79 & 1,11 & 0,67 & 0,90 \\
\hline $\begin{array}{c}\text { Outras manturas; reparación e instalación de } \\
\text { maquinaria e equipo }\end{array}$ & 0,86 & 1,06 & 0,93 & 1,37 \\
\hline Total de manufacturas & 0,95 & 0,99 & 0,81 & 1,02 \\
\hline
\end{tabular}

Fonte: elaboración do autor en base á EU KLEMS 2017

En canto ao signo positivo de $\delta_{1} E U R$, este parece suxerir que a entrada en circulación do euro como divisa común da eurozona non deteriorou a competitividade dos sectores manufactureiros españois con respecto aos alemáns (véxase a táboa 9 do anexo). Isto leva a lecturas son varias. Tal e como sinalan Mateo Tomé $(2015,2017)$ e Cárdenas del Rey (2017), durante a segunda fase de expansión do ciclo económico de España (1994-2007), os sectores que dirixiron o crecemento foron basicamente dous: as finanzas e a construción.

Porén, logo da crise 2007 e a recesión, os devanditos sectores perden a súa influencia, xa que para facer fronte ás fases do ciclo económico español, as reformas laborais de 2010 e de 2012 favoreceron un forte proceso de desvalorización interna ${ }^{8}$ que se materializou no descenso dos salarios reais para o total das manufacturas a unha taxa media acumulativa do -0,11\% anual entre 2007 e 2015 (véxase a táboa 4).

\footnotetext{
${ }^{8}$ Baste sinalar que, tal e como subliñan Perrotini-Hernández e Vázquez-Muñoz (2017), o verdadeiro instrumento utilizado polos bancos centrais para cumprir co obxectivo da estabilidade de prezos é a contención salarial e o descenso dos CLUR a través da redistribución regresiva do ingreso nacional. Logo, colígase que a política monetaria do Banco Central Europeo (BCE) foi un acicate que actuou beneficiando ao proceso de deflación salarial de España durante a recesión.
} 
O axuste á baixa dos salarios reais materializouse no descenso do índice dos CLUR do total das manufacturas de España de 93,28 en 2007 a 75,62 en 2015 (véxase a táboa 5). É dicir, os custos unitarios de produción caeron a unha taxa media acumulativa de -2,59\% anual (véxase a táboa 5).

Pola súa banda, para o período 2007-2015 o CLURR amosa unha taxa media acumulativa do 3,34\% e unha taxa de variación acumulada do 25,81\%.

Polo tanto, a industria manufactureira española tornouse máis competitiva con respecto á alemá, onde caben destacar os seguintes sectores:

i) outras manufacturas; reparación e instalación de maquinaria e equipo;

ii) maquinaria e equipo n.c.p;

iii) metais comúns e produtos metálicos, agás maquinaria e equipo;

iv) industria química; e

iv) Téxtil, prendas, coiro e calzado.

Malia todo, Guisán, Aguayo e Expósito (2018) subliñan que ao longo do período 20052012, a economía española rexistra un notable descenso do índice de produción industrial (en adiante, IPI), o cal é indicativo de que a estratexia de deflación salarial non actuou como o acicate para a expansión do produto manufactureiro. Así mesmo, para o devandito espazo de tempo obsérvase un estancamento do IPI no resto dos países da UE, incluída Alemaña. Por conseguinte, o aumento de CLURR debeuse á desaceleración no crecemento da produción nos sectores manufactureiros alemáns durante a recesión.

Por outra banda, cabe sinalar que a relación positiva entre o euro e a competitividade dos sectores manufactureiros españois descansa no concepto da destrución creativa de Schumpeter (1942). Máis exactamente, a crise e a recesión provocaron a eliminación das empresas e os sectores menos competitivos, deixando en pé unicamente a aquelas empresas e aqueles sectores da produción mellor dotados tecnicamente para facer fronte á competencia internacional. Así, a necesidade de capturar mercados estranxeiros logo de que a caída da demanda interna provocase o deseño de estratexias empresariais baseadas na innovación e na eficiencia técnica.

En resumo, a evidencia estatística apunta a que os termos reais de intercambio entre os sectores manufactureiros españois e alemáns atópanse regulados pola vantaxe absoluta de custo.

As táboas incluídas no Anexo amosan que hai suficiente evidencia estatística que revela que as tres variables do modelo se atopan cointegradas a longo prazo. Ou, expresado noutros termos, entre as tres variables existe unha relación estable a longo prazo.

\section{Conclusións}

Con base na teoría da vantaxe absoluta de custo de Shaikh, puídose construír un modelo de datos de panel dinámico conformado polos once sectores manufactureiros de España e de Alemaña. Deste xeito, contrastouse estatisticamente que as variables TCR, CLURR e INV atópanse cointegradas a longo prazo. Así mesmo, os vectores de cointegración verificaron que o TCR se amosa positivamente correlacionado cos CLURR e coa INV. Con isto, chégase ás seguintes conclusións:

1) A dinámica fundamental do TCR intrasectorial durante o período 1995-2015 ten como eixe de gravitación os niveis relativos dos CLUR. Polo tanto, infírese que a mellor posición competitiva das empresas manufactureiras alemás nace da súa vantaxe absoluta de custo en relación coas empresas españolas.

2) A vantaxe absoluta de custo das empresas alemás revela que gozan de mellores condicións de produción reproducibles cás empresas españolas. 
3) Despréndese que os sectores manufactureiros alemáns son máis competitivos con respecto aos sectores manufactureiros españois porque a diferenza na produtividade laboral é maior cá existente en salarios reais.

4) As condicións técnicas de produción xerais de Alemaña son superiores ás de España como consecuencia de factores técnico-produtivos e institucionais.

5) Mesmo cando a desvalorización salarial mellorou a posición competitiva dos sectores manufactureiros españois durante a recesión, o aumento do volume do investimento de bens de capital fai factible abatir os CLUR compensando o descenso dos salarios reais.

6) Urxe a mellora das condicións técnicas de produción do conxunto da economía española, para que as empresas manufactureiras arrostren a competencia internacional sen a esixencia de aplicar fortes axustes que menoscaben a capacidade de consumo e de aforro das familias.

\section{Referencias}

Becker, W., \& Dietz, J. (2004). R\&D cooperation and innovation activities of firmsevidence for the German manufacturing industry. Research policy, 33(2), 209-223.

Boundi Chraki, F. (2017). Determinantes de las relaciones reales de intercambio de España con Alemania (1970-2010). Un análisis econométrico de la ventaja absoluta de costo intrasectorial. Cuadernos de economía, 36(71), 489-520.

Breitung, J. (2001). The local power of some unit root tests for panel data. T. B. Fomby, R. Carter Hill, I. Jeliazkov, J. Carlos Escanciano y E. Hillebrand (eds.) Nonstationary panels, panel cointegration, and dynamic panels (pp. 161-177). Nueva York: Emerald Group Publishing Limited.

Cárdenas del Rey, L. (2017). Hechos estilizados del patrón de inversión en la economía española (1981-2013). Revista Galega de Economía, 26(2), 5-14.

Engle, R. F., \& Granger, C. W. J. (1987). Co-Integration and Error Correction: Representation, Estimation, and Testing. Econometrica, 55(2), 251-276.

Góchez Sevilla, R., \& Tablas, V. A. (2013). Tipo de cambio real y déficit comercial en Guatemala (1970-2007): un enfoque heterodoxo. México: CEPAL.

Götz, M., \&Jankowska, B. (2017). Clusters and Industry 4.0-do they fit together?. European Planning Studies, 25(9), 1633-1653.

Guerrero, D. (1995). Competitividad: teoría y política. Barcelona: Ariel.

Guisan, M. C., Aguayo, E., \& Expósito, P. (2018). Empleo sectorial y participación social en España y en Europa desde una perspectiva de género, Documento 119 de la serie Economic Development. Resumen. University of Santiago de Compostela. Faculty of Economics and Business. Econometrics

Johansen, S. (1988). Statistical analysis of cointegration vectors. Journal of economic dynamics and control, 12(2-3), 231-254.

Johansen, S. (1991). Estimation and hypothesis testing of cointegration vectors in Gaussian vector autoregressive models. Econometrica, 59(6), 1551-1580.

Kao, C. (1999). Spurious regression and residual-based tests for cointegration in panel data. Journal of econometrics, 90(1), 1-44.

Luque, V. A., \& Manso, E. P. (2015). Una interpretación del débil crecimiento de la economía alemana en el período 1995-2007. Revista de economía mundial, (41), 159-180.

Maddala, G. S., \& Wu, S. (1999). A comparative study of unit root tests with panel data and a new simple test. Oxford Bulletin of Economics and statistics, 61(S1), 631-652. 
Martínez-Hernández, F. A. (2010). An alternative theory of real exchange rate determination: theory and empirical evidence for the Mexican economy, 1970-2004. Investigación Económica, 69(273), 55-84.

Martínez-Hernández, F. A. (2017). The Political Economy of Real Exchange Rate Behavior: Theory and Empirical Evidence for Developed and Developing Countries, 1960-2010. Review of Political Economy, 1-31.

Mateo Tomé, J. P. (2015). Un análisis macroeconómico de la acumulación de capital en España durante la fase de expansión (1995-2007). Revista galega de economía, 24(3), 21 34.

Mateo Tomé, J. P. (2017). Distorsiones y desequilibrios en la dinámica de acumulación de la economía en España. Problemas del Desarrollo, 48(191), 55-82.

Muñoz de Bustillo, R., \& Fernández Macías, E. (2007). Producción y Tiempo: utilización de capacidad instalada en las empresas españolas. Estudios de economía aplicada, 25(1), 319320.

O'Mahony, M., \& Timmer, M. P. (2009). Output, input and productivity measures at the industry level: the EU KLEMS database. The economic journal, 119(538).

Pedroni, P. (1999). Critical values for cointegration tests in heterogeneous panels with multiple regressors. Oxford Bulletin of Economics and statistics, 61(S1), 653-670.

Pedroni, P. (2001). Fully modified OLS for heterogeneous cointegrated panels. En T. B. Fomby, R. Carter Hill, I. Jeliazkov, J. Carlos Escanciano y E. Hillebrand (eds.) Nonstationary panels, panel cointegration, and dynamic panels (pp. 93-130). Nueva York: Emerald Group Publishing Limited.

Perrotini-Hernández, I., \& Vázquez-Muñoz, J. A. (2017). Is the wage rate the real anchor of the inflation targeting monetary policy framework?. Investigación Económica, 76(302), 954.

Schumpeter, J. A. (1942). Capitalism, Socialism and Democracy. Estados Unidos: Routledge.

Seifert, H., \& Massa-Wirth, H. (2005). Pacts for employment and competitiveness in Germany. Industrial Relations Journal, 36(3), 217-240.

Shaikh, A. (2016). Capitalism: Competition, conflict, crises. Nueva York: Oxford University Press.

Stock, J., \& Watson, M. (1993). A Simple Estimator of Cointegrating Vectors in Higher Order Integrated Systems. Econometrica, 61(4), 783-820.

van Ark, B., \& Jäger, K. (2017). Recent Trends in Europe's Output and Productivity Growth Performance at the Sector Level, 2002-2015. International Productivity Monitor, (33), 823. 